ANUARIO DE Estudios MEdiEVAles 49/2, julio-diciembre de 2019, pp. 561-587

ISSN 0066-5061

https://doi.org/10.3989/aem.2019.49.2.07

\title{
LA ESTIGMATIZACIÓN DE LOS PECADORES CONTRA NATURA EN LA CASTILLA DEL SIGLO XIII: UNA APROXIMACIÓN DE HISTORIA CULTURAL AL TÍTULO XXI DE LA SÉPTIMA PARTIDA
}

\author{
THE STIGMATISATION OF SINNERS AGAINST NATURA \\ IN THIRTEENTH-CENTURY CASTILE: A CULTURAL HISTORY APPROACH \\ TO TITLE XXI OF THE SÉPTIMA PARTIDA
}

\author{
PLÁCIDO FERNÁNDEZ-VIAGAS ESCUDERO \\ Universidad de Sevilla \\ https://orcid.org/0000-0002-5011-4749
}

\begin{abstract}
Resumen: El presente artículo estudia los pecados contra natura contemplados en el título XXI del libro VII del Código de las Siete Partidas bajo una lógica interdisciplinar, empleando herramientas interpretativas de diferentes ciencias sociales. En esta tarea, propia de la historia cultural, nos sumergimos en los antecedentes legislativos que influyeron en la obra del legislador, así como en diferentes textos de la plena Edad Media, que abordaremos con detenimiento.
\end{abstract}

Palabras clave: partidas; sodomía; bestialismo; minorías; Castilla; Alfonso X; siglo XIII.

Abstract: This papers studies the sins against nature contemplated in Title XXI of Book VII of the Código de las Siete Partidas by means of an interdisciplinary approach. In order to do so, interpretative tools derived from different social sciences will be used. In this undertaking, characteristic of cultural history, the legislative antecedents that influenced the legislator will be analysed, as well as different texts of the High Middle Ages, which will be studied in detail.

Keywords: partidas; sodomy; bestialism; minorities; Castile; Alfonso X; $13^{\text {th }}$ century.

\section{SUMARIO}

1. Introducción.- 2. Los pecados contra natura en la Séptima Partida.- 3. Conclusiones.- 4. Bibliografía citada.

\section{INTRODUCCIÓN ${ }^{1}$}

Como en anteriores trabajos, abordamos en el presente estudio las estructuras de significación contenidas en el código alfonsí empleando herramientas interpretativas de diferentes ciencias sociales, que enriquecen nuestra

\footnotetext{
${ }^{1}$ Las fuentes empleadas en esta obra serán citadas de forma abreviada en las notas al pie, seguidas del número de la ley o capítulo, salvo cuando se indique la página o el folio concreto de la edición que manejamos. Para la comprensión de las mencionadas citas, téngase en

Citation / Cómo citar este artículo: Fernández-Viagas Escudero, Plácido (2019), La estigmación de los pecadores contra natura en la Castilla del siglo XIII: una aproximación de historia cultural al título XXI de la séptima partida, "Anuario de Estudios Medievales" 49/2,pp. 561-587. https://doi.org/10.3989/aem.2019.49.2.07

Copyright: (C) 2019 CSIC. Este es un artículo de acceso abierto distribuido bajo los términos de la licencia de uso y distribución Creative Commons Reconocimiento 4.0 Internacional (CC BY 4.0).
} 
investigación y permiten realizar un estudio que transciende el mero análisis técnico-jurídico. De esta forma, e inspirados en la llamada descripción densa ${ }^{2}$, propia de los estudios etnográficos y emparentada en el mundo del derecho con la interpretación sociológica de las normas, nos sumergimos en un vasto número de fuentes, no sólo jurídicas, para interpretar las normas del título XXI de la Séptima Partida en su contexto cultural y extraer unas conclusiones más precisas en nuestra tarea investigadora.

Al margen de esta aproximación general y para una investigación específica en nuestro análisis, recurrimos a categorías y herramientas interpretativas propuestas por diferentes disciplinas, en la medida en que nos sean de utilidad y no planteen contradicciones irresolubles en el marco teórico. Con esta premisa, y para comprender la lógica del esquema de persecución de los sodomitas recogido este título XXI, nos apoyamos en la categoría del chivo expiatorio propuesta por R. Girard para analizar la atribución de responsabilidad a grupos determinados de individuos, respecto de desgracias y crisis colectivas que acontecieron durante la Edad Media ${ }^{3}$. También encontramos utilidad en la categoría del estigma, en los términos estudiados por E. Goffman $^{4}$, para analizar los motivos de la identidad deteriorada de estos sujetos en el contexto cultural que nos interesa.

Por lo tanto, emprendemos con este artículo una empresa de historia cultural, que se apoya en una vastedad de documentos de la época, principalmente del siglo XIII, para disponer de un fondo interpretativo suficiente con el que analizar las normas del código alfonsí que requieren de nuestro interés. De esta manera, afrontamos el objetivo de comprender las leyes del mencionado título XXI, del libro VII, en su sentido original, así como el de estudiar las dinámicas de persecución contra determinados individuos en la legislación castellana medieval. Con ello, procuramos contribuir al estudio de unas leyes que, en mayor o menor medida, ya han sido abordadas por diversos autores, cuyas obras mencionaremos a lo largo de este artículo, tales como J.A. Solórzano Telechea, M.T. López Beltrán, R.J. González-Casanova,

cuenta que empleamos las siguientes abreviaturas: $\mathrm{A}=$ Alcalá; $\mathrm{C} .=$ Crónica; $\mathrm{CEM}=$ Cántigas de escarnio y maldecir $;$ Co. = Códice; Con. = Concilio; $\mathrm{CSM}=$ Cántigas de Santa María; D. = Doctrinal; F. = Fuero; f. = folio; GE = General Estoria; H. = Historia; L. = Liber $/$ Llibre; $\mathrm{LCIE}=$ Libro conplido de los iudizios de las estrellas; $\mathrm{P} .=$ Pasionario; $\mathrm{PCG}=$ Primera Crónica General; $\mathrm{V}$ = Vidal .

Por último, las ediciones de las fuentes que manejamos serán mencionadas de manera desarrollada dentro del apartado de bibliografía citada.

${ }^{2}$ Geertz 2003. Véase cómo en anteriores artículos hemos trabajamos de una manera similar los textos extraídos del código alfonsí, inspirados en la descripción densa de Geertz, en Fernández-Viagas 2016, 2017a, 2017b, 2017c.

${ }^{3} \mathrm{Cf}$. Girard 1986.

${ }^{4}$ Cf. Goffman 2006. 
J.M. Castrillo de la Fuente y A.I. Carrasco Manchado, entre otros, como también nos apoyaremos en las aportaciones de M. Jordan, J. A. Brundage, J. Hopman, M. Goodich, J. Boswell y de aquellos otros autores que, aun con diferentes enfoques o puntos de vista, han contribuido al estudio de la persecución de los homosexuales en la Europa de la época.

\section{LOS PECADOS CONTRA NATURA EN LA SÉPTIMA PARTIDA}

La Séptima Partida configuraba la fornicación entre hombres y la fornicación con bestias como actuaciones delictivas diferenciadas en el título XXI, pero bajo la misma categoría de pecados de luxuria contra natura, ya que ambas atentaban contra los mismos bienes jurídicos protegidos, cuales eran la castidad y la natura. Como comprobaremos, el legislador, apoyándose en el interés divino hacia estos valores ${ }^{5}$, reguló estas cuestiones bajo un enfoque que transcendía lo meramente jurídico, y que nos traslada al ámbito de lo teológico.

En cuanto a la fornicación entre hombres, el legislador la denominaba pecado sodomítico y establecía que era aquel en que caen los omes, yaciendo vnos con otros, contra natura, e costumbre natural ${ }^{6}$. Esta definición, y

\footnotetext{
${ }^{5}$ Respecto de la castidad, téngase en cuenta que en el proemio del título XIX, del libro VII, podemos leer lo siguiente: "Castidad es vna virtud que ama Dios, e deuen amar los omes. Ca, segund dixeron los sabios antiguos, tan noble, e tan poderosa es la su bondad, que ella sola cumple para presentar las animas de los omes, e de las mujeres castas, ante Dios", presumiblemente bajo la inspiración de la legislación justinianea, $c f$. Novelas 14.1 .

La articulación de la castidad bajo un enfoque teológico semejante podemos también encontrarla en diferentes textos peninsulares de la época, especialmente en los escritos de Ramón Llull, como puede comprobarse en D. Pueril 61.8 y en Felix 7.8. No obstante, para un estudio en mayor profundidad sobre esta materia, $c f$. Fernández-Viagas $2017 \mathrm{c}$.

En cuanto al enfoque teológico de la natura, véase lo establecido por el legislador en la ley I, del título XXIV, del libro IV: "Natura es una virtud que face seer todas las cosas en aquel estado que Dios las ordenó; et naturaleza es cosa que semeja á la natura, et que ayuda á seer et á mantener todo lo que decende della". En muy semejantes términos, $c f$. Partidas 1.4.67.

${ }^{6}$ Partidas 7.20.pr. Véase la similitud de esta norma con lo establecido, dentro del repertorio literario alfonsí, en $G E$ 1.1: 250, que concebía al pecado sodomítico como un acto cometido por los varones contra la ley y contra natura, en los siguientes términos: "E esto dizié Nuestro Señor porque la yente de Sodoma e de Gomorra eran tan abondados de todas cosas que podrién seer pora vicio de omne, assí como diz Paulo Orosio, que creció en ellos sobervia de fazer luxuria en sí mismos desguisada contra ley e contra natura".

En cuanto a los sujetos activos, al tenor de la norma de las Partidas, las mujeres quedaban por lo tanto al margen de este delito, así como en el derecho justinianeo del que bebieron las Partidas en la regulación de este delito ( $c f$. Novelas 141.1), y al igual que, como hemos visto, se contemplaba en la historiografía bíblica alfonsí. Pero también se seguía esta línea en el derecho peninsular previo, como se comprueba en el Liber Iudiciorum (cf. L. Iudiciorum 3.5.5) y en el Fuero Real ( $c f$. F. Real 4.9.2), así como puede ello deducirse de la regulación de los fueros municipales que contemplaban este ilícito en la familia de Cuenca-Teruel antes del siglo XIV
} 
la regulación de la materia, han de enmarcarse en un proceso en el que, como señaló R. Moore en su ya clásico estudio sobre la formación de una sociedad represora medieval, estaban cristalizando distintas construcciones teóricas que definieron con mayor precisión y que clasificaron como enemigos de la sociedad a varios agentes sociales, entre los que se encontraban los homosexuales, y que justificaban su represión por parte de las instancias de poder? Efectivamente, durante la Plena Edad Media, algunos teólogos y canonistas, identificaron este pecado con consternación, elaborando un cuerpo doctrinal específico que iría enriqueciéndose con los años ${ }^{8}$. En materia

(cf. F. Cuenca 332 (12.28) Co. Valentino 2.2.22, F. Iznatoraf 304, F. Zorita 302, F. Úbeda 30.5, F. Alcaraz 4.81, F. Alcázar 285, F. Alarcón 285, F. Plasencia 108, F. Teruel 399, F. Andújar 280, F. Béjar 386 y F. Sabiote 305), En todo caso, siglos después de la redacción de las Partidas, el glosador Gregorio López entendería que dicho título XXI admitía una interpretación no literal en base a la cual podía castigarse a las mujeres que pecaban yaciendo unas con otras, contra natura, $c f$. López 1576, glosa a Partidas 7.21.pr.

Por otra parte, respecto de la acción típica, por yacer hemos de deducir, como ya hicimos en el pasado al interpretar dicha voz repetida en diferentes títulos de la Séptima Partida, que tal verbo aludía a una relación de naturaleza sexual con penetración ( $c f$. Fernández-Viagas 2017b; 2017c). Téngase en cuenta que, en el título XX de la Séptima Partida, que regulaba el delito de violación, se hacía un uso indistinto de los términos yacer por fuerza y pasar por fuerza $(c f$. Partidas 7.20.pr y 7.20.3), e, indudablemente, lo que nos sugiere la voz pasar, en dicho contexto, es la acción sexual de penetrar. Por otra parte, en Partidas 7.21.2 se mencionaba que un sujeto faze y el otro consiente, lo que nos sugiere una relación sexual con penetración, como acción típica, con un sujeto activo y otro pasivo. Al margen de ello, lo cierto es que las leyes no nos aportan mayor concreción, pero, dada la naturaleza del delito en cuestión, bien podemos presumir que el legislador tenía en mente la penetración anal con el miembro viril al regular la materia. En este sentido, téngase en cuenta que la penetración anal con un palo no era contemplada como un delito contra la castidad en el derecho foral castellano previo a las Partidas, sino que tal acción tenía transcendencia penal en tanto que se configuraba como un denuesto de hecho contra el varón, $c f$. nota 24.

${ }^{7}$ Cf. Moore 1989.

${ }^{8}$ Para localizar las principales opiniones de estos autores en varias de las fuentes de mayor relevancia:

- Respecto de Pedro Damiano, véase su Liber Gomorrhianus, y muy particularmente su capítulo I, dedicado a los diversos pecados contra natura que identificaba el autor, con una concreción no conocida en su tiempo.

- Respecto del Decretum de Burcardo de Worms, cf. Decretum 17.34-35 y 17.54.

- Respecto del Decretum de Ivo de Chartres, cf. Decretum 9.92.

- Respecto de los pecados sexuales contra natura en el Decretum de Graciano, cf. Decretum C. 32 , Q. 7, c. 12-14.

- Respecto de las diferentes formas de pecado contra natura en el Liber poenitentialis de Alain de Lille, que incluían el bestialismo y la sodomía, entre otras formas de relaciones sexuales, $c f$. Liber 2.125 (véase otra mención sobre el pecado contra natura en Liber 1.4).

- En cuanto al territorio peninsular, véase la opinión de Raimundo de Peñafort sobre la sodomía en su Summa de Poenitentia, cf. Summa 3.32.6 y 3.34.42.

Más allá de estas referencias seleccionadas, para un estudio más amplio, sobre la estigmatización de los homosexuales en esta época y sobre la progresiva elaboración del concepto de pecado contra natura, véanse las siguientes fuentes secundarias, no siempre coincidentes en sus conclusiones, pero de interés indudable para el investigador, en una aproximación general a la materia: Camocho 2012; Jordan 2002; Crompton 2004; Hopman 2000; Molina 2010; Borrillo, 
de derecho canónico, fue en este período de la Plena Edad Media cuando encontramos la primera condena en un concilio ecuménico del pecado contra natura, en concreto en el III Concilio de Letrán (1179), aunque en él no se establecieron exactamente las prácticas que caían bajo dicho concepto ${ }^{9}$. En este proceso histórico, en el que poco a poco estaba dotándose de un contenido más elaborado al llamado pecado contra natura, las Partidas, concluidas antes de la Summa Theologiae de Tomás de Aquino según la opinión mayoritaria ${ }^{10}$, configuraron en clave penal dos actos sexuales definidos como contra natura, como son el acto de sodomía y también el de bestialismo, delito este último que no había sido regulado con anterioridad en el derecho no eclesiástico español, como analizaremos con detenimiento.

Ya en el siglo XIII encontramos diversos fueros peninsulares, como el de Cuenca, que castigaban con la muerte a los hombres que incurriesen en el llamado pecado sodomítico, endureciendo el castigo previsto en el antiguo Liber Iudiciorum ${ }^{11}$. Ciertamente, durante en el transcurso del siglo XIII, la legislación en contra de este pecado se hizo frecuente en los fueros extensos de Cuenca-Teruel, quizás elevando al derecho foral escrito una práctica judicial de la que aparentemente no tenemos noticia, y, en todo caso, bajo la influencia

Colas 2005; Burgwinkle 2004; Spencer 2005; Boswell 1993; Johansson, Percy 2000; Fone 2000; Castrillo 2009; Gauthier 1977; Carrasco 2008; Bazán 2007; Goodich 1979.

${ }^{9} \mathrm{Cf}$. III Con. Letrán 11 (canon que sería insertado posteriormente en las Decretales de Gregorio IX, $c f$. Decretales 3.1.1). Téngase en cuenta que, en el posterior concilio ecuménico, el Concilio IV de Letrán se refirió a este pecado como causa de la ira divina en su canon XIV, en unos términos más imprecisos: "Ut clericorum mores et actus in melius reformentur continenter et caste vivere studeant universi, praesertim in sacris ordinibus constituti, ab omni libidinis vitio praecaventes, maxime illo, propter quod ira Dei venit de coelo in filios diffidentiae, quatenus in conspectu Dei omnipotentis puro corde ac mundo corpore valeant ministrare".

${ }^{10}$ Sobre la fecha de redacción de las Partidas, $c f$. Craddock 1981. La línea mayoritaria, y que apunta a una primera conclusión de las Partidas en el año 1265, parece también asumida por J. Ferreiro Alemparte y G. Martin, autores de interesantes trabajos que ponen en relación las Partidas o las fuentes utilizadas por éstas con obras de Tomás de Aquino, $c f$. Ferreiro 1988 y Martin 2000). A este respecto, téngase en cuenta que hoy es minoritaria la opinión de A. García-Gallo, que data a las Partidas en una fecha muy tardía, más allá del reinado de Alfonso X, $c f$. Bermejo 2011.

Respecto de la Summa Theologiae, lo cierto es que la misma proporcionó una fundamentación ideológica de gran aceptación y definió con mayor precisión al pecado contra natura, distinguiendo cuatro categorías dentro del mismo: La masturbación o molicie, el acto de bestialismo, el acto homosexual y el acto heterosexual no orientado a la reproducción, $c f$. Summa 2-2, quest. 154, art. 11 corpus. En todo caso, sólo podríamos considerar que la elaboración conceptual del pecado contra natura de Tomás de Aquino en esta obra tuvo alguna influencia en las Partidas de aceptar una datación tardía en la redacción de este título XXI, del libro VII.

${ }^{11}$ Cf. L. Iudiciorum 3.5.5. Respecto de los fueros de la familia de Cuenca que penaban al pecado sodomítico, véase la nota 6. Fuera de los territorios de Castilla, León y de Aragón, pero dentro del territorio peninsular, la sodomía era regulada antes del siglo XIV tanto en el derecho foral de Valencia ( $c f$. F. JaimeI 22, 63, 1220 y 1223) como en Cataluña ( $c f$. F. Tortosa 1.8.1). Respecto de Cataluña, para un estudio de la legislación y de las evidencias judiciales respecto de la sodomía desde el siglo XIII hasta el siglo XVIII, y que, por lo tanto, se adentra en el ámbito temporal de nuestro interés, $c f$. Riera 2014. 
en su redacción del recuperado derecho romano oriental y de la elaboración conceptual de los teólogos, y a la sombra de una cuestión de orden psicosocial, consistente en el temor cada vez más difundido en la época de que el acto homosexual desencadenase la ira divina contra toda la comunidad ${ }^{12}$. No en vano, y recogiendo esta cuestión ya arraigada culturalmente, las Partidas establecieron que de tal acto nacen muchos males en la tierra do se faze, e es cosa que pesa mucho en Dios con el. E sale ende mala fama, non tan solamente a los fazedores, mas aun a la tierra, do es consentido ${ }^{13}$.

En esta misma línea, y acudiendo a la fuente de autoridad de los textos bíblicos, se justificaba la regulación del acto homosexual en los siguientes términos:

Sodoma, e Gomorra, fueron dos ciudades antiguas pobladas de muy mala gente, e tanta fue la maldad de los omes que biuian en ellas, que porque usauan aquel pecado que es contra natura, los aborrescio nuestro Señor Dios, de guisa que sumio ambas las ciudades, con toda la gente que y moraua, e non escapo ende solamente, si non Loth e su compaña, que non auian en si esta maldad e de aquella ciudad Sodoma, onde Dios fizo esta marauilla, tomo este nome este pecado, a que llaman sodometico. E deuese guardar todo ome deste yerro, porque nacen del muchos males, e denuesta, e desfama a si mismo el que lo faze. Ca por tales yerros embia nuestro señor Dios sobre la tierra donde lo fazen fambre, e pestilencia, e tormentos, e otros males muchos, que non podria contar $^{14}$.

${ }^{12}$ Cf. Brundage 2000, p. 374.

${ }^{13}$ Partidas 7.21.pr. En cuanto a la ira divina desplegada no sobre un pecador en concreto, sino sobre toda la comunidad, podemos comprobar cómo la misma se proyectaba también sobre toda la comunidad a causa del pecado de lujuria en la historiografía alfonsí, no sólo en la narración del relato de Sodoma y Gomorra, sino en la explicación de la caída de los godos. Sobre este particular, $c f . P C G 565$ y 592 y GE 3.1: 313. Respecto de la caída de los godos a causa del castigo divino por los pecados de lujuria, éste se trata de un tópico recurrente en la historiografía pre alfonsí, como puede comprobarse en diversas crónicas previas, como en C. Alfonso III, p. 9, C. Silense p. 72 y C. Mundi 4.3.

Junto con la lujuria, la idolatría era el otro gran pecado que desatada la ira divina contra la comunidad en la historiografía alfonsí, $c f$. $G E$ 1.2: 377-378 y 3.1: 495. En relación con lo dicho, véase cómo este cuerpo historiográfico vinculaba ambos pecados en $G E$ 3.2: 445, bajo la afirmación de que "la demanda de los ídolos comienço es de fornicación".

Por último, de esta norma transcrita de la Séptima Partida se deduce, como también de lo dispuesto en la primera ley de este título, que por su práctica sexual delictiva los sodomitas quedaban infamados de hecho, sin necesidad de declaración judicial alguna, como podemos ver confirmado en Partidas 7.6.1. Sobre esta cuestión, $c f$. López 1576, glosa a Partidas 7.6.1 y Solórzano 2015. Respecto de la infamia aparejada a este delito en las Partidas, véase también, de este último autor, Solórzano 2006, p. 150; 2007, p. 404; 2008, pp. 190-191; 2012, p. 292

${ }^{14}$ Partidas 7.21.1. El relato de la destrucción de Sodoma y Gomorra vinculado con el acto homosexual, concebido como pecado contra natura, también se realiza en la producción alfonsí, más allá de los textos jurídicos, en la General Estoria, como se comprueba en GE 1.1: 250 y 254. 
Para A. I. Carrasco Manchado el influjo del mito bíblico de Sodoma y Gomorra descansaba en que, para la mentalidad medieval, éste era un relato histórico y, por lo tanto, altamente ejemplarizante ${ }^{15}$. Nosotros podemos añadir que, bajo un enfoque antropológico, la fuerza de este relato no descansaba únicamente en la creencia de su historicidad, sino también en su exposición en forma de mito, dada la capacidad de esta estructura de carácter cultural para ordenar la experiencia humana ${ }^{16}$. Más allá de esta apreciación, resulta necesario comentar el análisis de teoría política realizado sobre esta norma por la mencionada autora. Para A. I. Carrasco Manchado, con la divulgación del relato de Sodoma y Gomorra, se dan las condiciones para que surta efecto la estrategia de la culpabilización comunitaria del reino que pone en marcha la norma, útil para el sostenimiento del poder monárquico, cuyo origen y ejercicio se fundamentaría en la necesidad de preservar la ley divina ${ }^{17}$.

A este respecto, téngase en cuenta que, a semejanza del derecho romano justinianeo ${ }^{18}$, las Partidas atribuían una responsabilidad a toda la comunidad por las desgracias desatadas, bien por consentir o bien por no perseguir suficientemente estas conductas homosexuales, y por ello en el proemio del título XXI se aludía precisamente al consentimiento comunitario con este pecado que propiciaba el enojo divino y la mala fama sobre la tierra, pero también se dejaba meridianamente claro en estas normas que, más allá de esta responsabilidad colectiva, existía una responsabilidad individual de los sodomitas, que se encontraba en el núcleo de crisis y que aborrecía especialmente la divinidad, como estamos viendo. Dicho lo cual, cabría entonces proponer un análisis de esta construcción simbólica del derecho alfonsí, que justificaba la persecución y el castigo a muerte de estos delincuentes, con el auxilio de la categoría ampliamente estudiada por el historiador R. Girard del chivo expiatorio ${ }^{19}$, en tanto que en la época pareciera que nos encontramos con los elementos esenciales que, en opinión del mencionado autor, explican

\footnotetext{
${ }^{15}$ Cf. Carrasco 2008, p. 134.

${ }^{16}$ Cf. Geertz 2003,p. 97. Respecto de los mitos medievales, según I. Moore, no sólo fueron asociados los homosexuales con relatos míticos durante este período, sino también los restantes sujetos perseguidos fueron conectados con otra serie de mitos, que los identificaban con agentes de contaminación social ( $c f$. Moore 1989, p. 119).

${ }^{17}$ Carrasco 2008, p. 134. Una lectura en clave política diferente es la que realiza J. Hopman de una norma justinianea semejante, que empleaba el relato de Sodoma y Gomorra en la configuración del delito de sodomía y en la que se espejaban precisamente el proemio y la ley I, del título XXI de la Séptima Partida (como veremos posteriormente). Para dicho autor, el mencionado relato bíblico servía políticamente a la autoridad imperial, en la medida en que eximía de responsabilidad al gobierno por las catástrofes y desgracias en su territorio, $c f$. Hopman 2000, p. 116.

${ }^{18}$ Cf. Novelas 141.1 , in fine.

${ }^{19} \mathrm{Cf}$. Girard 1986.
} 
el esquema de persecución del pensamiento mágico medieval a determinados grupos humanos o chivos expiatorios. Como es conocido, tales elementos son la acusación de crímenes estandarizados cometidos por estos sujetos perseguidos (la penetración anal entre hombres en este caso), las crisis y calamidades padecidas por toda la comunidad tras la realización de estos crímenes estandarizados, así como los rasgos victimarios asociados a estos sujetos $^{20}$. Por último, bajo este marco simbólico que venimos analizando, resulta perfectamente comprensible que la acción para acusar a los varones sodomitas fuese pública ${ }^{21}$, dada la repercusión pública del propio ilícito, acentuada por las desgracias anunciadas a la comunidad, si no se perseguían tales crímenes.

Relacionado con lo anterior, muestra de la conceptualización negativa de los homosexuales de la época, que también podemos analizar desde el concepto antropológico del estigma, en tanto que portadores de un atributo fuertemente desacreditador ${ }^{22}$, es la gran cantidad de fueros municipales en los que, entre los denuestos más graves que podía recibir un hombre, se recogía el de sodomita o bien, más frecuentemente, el de fodido o fi de fodido, u otras voces semejantes, en la configuración del delito de denuestos ${ }^{23}$, así como la

\footnotetext{
${ }^{20}$ Para un estudio sobre la asociación de los sodomitas con el paganismo, el islamismo y la herejía en la mentalidad de la época, rasgos victimarios todos ellos, $c f$. Burgwinkle 2004 , p. 46; Boswell 1993, p. 272; Bazán 2007; Carrasco 2008, p. 118; Madero 1992, p. 124; Brundage 2000, p. 451; Moore 1989, p. 110; Fone 2000, pp. 148-155; Hopman 2000, p. 118, entre otros.

Respecto de los escritos peninsulares, véase a modo de ejemplo los casos recogidos de moros sodomitas en las cantigas de escarnio y maldecir gallego-portuguesas, $c f$. $C E M$ 116, 117 , 186 y 295, así como la asociación entre sodomía y herejía en el fuero de Molina de Aragón, $c f$. F. Molina 20.1 y, con anterioridad, tan pronto como en el siglo X, la afirmación del mártir san Pelayo de que los musulmanes eran afeminados en P. Hispánico 24.8. Por otra parte, en cuanto a la asociación de los lujuriosos con el paganismo y la herejía en la producción alfonsí, $c f$. nota 13 .

${ }^{21}$ Cf. Partidas 7.21.2.

${ }^{22}$ En este caso, el atributo desacreditador consistía en un defecto del carácter, por utilizar la terminología propuesta por E. Goffman, $c f$. Goffman 2016, p.14.

${ }^{23}$ Dividiremos la exposición por familias de fueros o grupos afines, como de costumbre:

- Respecto de la familia de fueros de Cuenca-Teruel: F. Cuenca 12.3, Co. Valentino 2.2.2, F. Teruel 369, F. Iznatoraf 275, F. Andújar 263, F. Zorita 274, F. Alcaraz 4.55, F. Alcázar 261, F. Alarcón 261, F. Úbeda 30.1, F. Béjar 356, F. Plasencia 74 y F. Sabiote 277. El fuero de Brihuega utiliza el término nombre uedado, que bien podemos interpretar como sodomita ( $c f$. F. Brihuega 92). Como puede comprobarse, no mencionamos aquellos fueros que desbordan el ámbito temporal del siglo XIII, para lo cual empleamos como referencia la cronología de Barrero, Alonso 1999.

- Respecto de la familia de Coria: F. Coria 183, F. Usagre 189, F. Castell-Rodrigo 183, F. Alfaiates 184, F. Castello-Bom 188, F. Castell-Melhor 122 y F. Cáceres 186.

- Respecto de la familia de Sahagún: F. Allariz 33, F. Bonoburgo 31, F. Oviedo y F. Ribadavia 37 (bajo el término majorum nominum).

- Respecto de la familia del fuero de León: F. Parga 14, F. Llanes 13 y F. Milmanda 26.
} 
aparición en la familia de Cuenca-Teruel de un delito de denuesto de hecho consistente en la introducción de un palo por el ano del denostado, acción que asociaba a este sujeto con la práctica pasiva de la sodomía ${ }^{24}$. Y no podemos olvidar tampoco el carácter peyorativo o la visión negativa con la que mayoritariamente se trataba a estos sujetos en la literatura no jurídica de la época ${ }^{25}$.

En cuanto a la pena corporal establecida por las Partidas para los sodomitas, se disponía la pena de muerte para los culpables, pero no se castigaba a los hombres que hubieran sido forzados ${ }^{26} \mathrm{y}$ a los menores de catorce años, los primeros por haber participado en el acto sin intención y los segundos por carecer de suficiente entendimiento ${ }^{27}$. La pena de muerte a los sodomitas se encontraba ya muy difundida en el derecho foral para cuando fueron redactadas las Partidas y no supuso ninguna novedad en el entramado jurídico de la época. En este sentido, y respecto de la familia de Cuenca-Teruel, la pena que más se repetía era la de que los culpables muriesen quemados ${ }^{28}$. Por su parte, el Fuero Real imponía a los sodomitas primero la pena infamante de ser castrados ante todo el pueblo, lo que suponía materializar el castigo en la parte del cuerpo manchada por el pecado ${ }^{29}$, y en segundo lugar la pena de

- Más allá de estas familias, y sin ánimo de agotar la casuística: F. Guadalajara 115 (aquí nuevamente se usa el término nonbre vedado), F. A. Henares 111, F. Uclés 45 y 186, F. Ledesma 184, F. Molina 20.1, F. Medinaceli 27 y F. Lara 11.

- Sin ánimo de agotar la casuística, en lo que se refiere al derecho aragonés y más allá de los fueros de la familia de Cuenca-Teruel, $c f$. V. Mayor 9.60, C. Villarense 39 (bajo el término turpe nomine) y F. Alfambra 47 (nombre uedado), mientras que en el derecho portugués, $c f$. F. Santarém (nome deuedado) y en el derecho navarro, $c f$. F. Peralta 45.

${ }^{24} \mathrm{C} f$. F. Cuenca 338 (12.34), Co. Valentino 2.2.28, F. Béjar 393, F. Zorita 307, F. Úbeda 30.6, F. Iznatoraf 311, F. Sabiote 312, F. Andújar 286, F. Huete 259, F. Alcaraz 4.87, F. Alcázar 291, F. Alarcón 291, F. Plasencia 123, F. Teruel 398 y F. Albarracín. Respecto de la representación pictórica de este denuesto de hecho en el manuscrito del siglo XV del fuero latino de Teruel, en la Biblioteca Nacional de Madrid, $c f$. Navarro 2015, p. 69.

${ }^{25}$ Respecto del repertorio alfonsí y del atributo fuertemente desacreditador de los sodomitas o afeminados, $c f . C S M 235, L C I E$ ff. $156 \mathrm{v}$ y $157 \mathrm{r}$ y $G E 3.1: 521$ y 3.2: 55 . Por otra parte, y por la relevancia en materia jurídico penal de la expresión empleada, hemos de traer a colación la falsa acusación recogida en la Historia Compostelana al obispo Ataulfo por sodomía, concebida al mismo tiempo como un vicio y un delito, que movía a la ira del rey. Tan furioso puso al rey oír tal acusación, que condenó al obispo a morir despedazado por un toro, como recoge este texto historiográfico del siglo XII, $c f$. H. Compostelana 1.2.2. Para un estudio de este relato y de sus orígenes, $c f$. Callón 2011, pp. 41-50.

${ }^{26}$ Tampoco en el Liber Iudiciorum se penaba al que hubiera realizado sin su voluntad este pecado, $c f$. L. Iudiciorum 3.5.5.

${ }^{27}$ Cf. Partidas 7.21.2.

${ }^{28}$ Véase las leyes mencionadas en la nota 6 . Todos estos fueros, además, fijaban la misma pena para el que falsamente afirmase haber pecado contra natura con otro hombre en la misma ley o en la siguiente.

${ }^{29}$ Esta práctica de ejecutar la pena sobre la parte del cuerpo empleada para cometer el pecado, como se aprecia en la fazaña del hombre de Castro Urdiales que perdió la mano por penetrar con ella a una mujer ( $c f . F$. Viejo 2.2.2 y L.Fueros 303), no era extraña en Castilla en lo que al 
muerte al tercer día de la castración, pena que había de ejecutarse colgando por las piernas a los culpables. Para aumentar la coacción sobre la sociedad, dicho fuero disponía que los así colgados no debían ser retirados nunca del lugar, con lo que sus cadáveres permanecerían ante los ojos del resto el mayor tiempo posible ${ }^{30}$. M. T. López Beltrán, respecto de las Partidas, entiende que la ejecución de la pena de muerte, de la que nada se decía en dicho código, dependería del juez que resolviera la causa, debido al poder de arbitrio judicial concedido genéricamente en la ley VIII, del título XXXI, del libro VII, por lo que bien podría celebrarse una ceremonia del castigo similar a la prevista en el Fuero Real, al amparo de estas normas ${ }^{31}$. En todo caso, y bajo un análisis desde la sociología de las religiones, con la muerte ejecutada por los verdugos nos encontramos con la violencia santa y legítima ordenada por el sistema judicial $^{32}$, que, en un enfoque de corte durkheimiano, supondría una medida de separación radical del delincuente, concebido como ser impuro a causa de su atentado, respecto del mundo profano y necesitado de protección ${ }^{33}$.

Por otro lado, en cuanto a la fuente principal de esta regulación, pueden esgrimirse dos interpretaciones. Diversos autores consideran que las normas de las Partidas sobre este asunto devienen del derecho romano justinianeo ${ }^{34}$, mientras que, por su parte, R. M. Mérida pareciera sostener que el código alfonsí bebió en este punto de la herencia jurídica visi-

castigo de los delincuentes sexuales se refiere. Más concretamente, en el delito de sodomía, ya el Fuero Juzgo, recogiendo lo dispuesto en el derecho visigodo, penaba con la castración a los sodomitas, entre otras penas que no incluían la muerte, $c f$. F. Juzgo 3.5.5.

${ }^{30}$ Cf. F. Real 4.9.2. Véanse las semejanzas de esta norma con lo dispuesto posteriormente por el fuero de Soria ( $c f$. F. Soria 546).

${ }^{31} C f$. López 2010, p. 179. En este sentido, para contextualizar la afirmación del investigador G.J. Sáez Martínez de que en las Partidas se condenaba a muerte al sodomita "sin ningún tormento previo" ( $c f$. Sáez 2015, p. 143), cabría añadir esta posibilidad de que el juez, en ejercicio de su arbitrio y de acuerdo con lo dispuesto en el código alfonsí, pudiese ordenar mayores castigos o diferentes medidas contra el pecador. De esta manera, la afirmación de G.J. Sáez Martínez no es inexacta, pero entendemos que merece ser glosada en esta dirección.

${ }^{32}$ Sobre este carácter sagrado y legítimo de la violencia hacia los delincuentes ordenada por los jueces, bajo una aproximación ya clásica de la sociología, $c f$. Girard 1972.

${ }_{33}$ Bajo una aproximación de la sociología las religiones, respecto de la adquisición de la impureza por el individuo como consecuencia de la realización de delitos graves, así como respecto la necesidad de ejecutar sobre éste la pena de muerte, en aras de una separación radical entre el ser impuro y la comunidad, $c f$. Caillois 1984, pp. 43-49.

Por otra parte, más genéricamente, en cuanto a la necesidad de interponer un abismo simbólico que mantenga separadas las cosas sagradas (ya sean puras o bien impuras) de las profanas, a través de la imposición de tabúes de contacto, véanse los trabajos ya clásicos de Otto 1965; Durkheim 1968; Eliade 2014; Leeuw 1964; Widengren 1976, por citar algunos indispensables. Para un repaso por las principales aportaciones en esta materia, $c f$. Ries 1989.

${ }^{34}$ Cf. Camocho 2012, p. 103; Carrasco 2008,p. 133; Ortega 2011, p. 98. 
gótica $^{35}$. Ambas interpretaciones resultan razonables, sin embargo, nos inclinamos por preferir al derecho romano como fuente privilegiada, dada la mención del delito como pecado contra natura en las Novelas de Justiniano, que también relatan la destrucción de Sodoma y presentan la amenaza del castigo divino a toda la comunidad, bajo un esquema narrativo y unas consecuencias penales muy similares a las configuradas por los juristas de Alfonso X en la Séptima Partida ${ }^{36}$. Dicho lo cual, es cierto que la exclusión de responsabilidad penal del sujeto que participara por fuerza en el acto sodomítico no aparece en el derecho justinianeo y sí en el Liber Iudiciorum, precisamente como en las Partidas. Pero ello no implica necesariamente que el código visigótico fuera empleado como fuente en este punto, ya que en el derecho penal alfonsí se aprecia un interés general, que no se ciñe a este título XXI, por subjetivar la responsabilidad penal, a causa de la influencia del derecho común y de la vinculación entre el pecado y el delito en el derecho de la época ${ }^{37}$.

Por otra parte, esta legislación de las Partidas convivía con una literatura homoerótica que, si bien era ciertamente minoritaria, se veía reflejada en distintos géneros y en distintos territorios cristianos de la península. Ello nos indica que, a pesar de que durante el siglo XIII la legislación estaba siendo particularmente virulenta respecto de estas prácticas y de que sobre los homosexuales recaía una fuerte carga estigmatizante, existía una corriente de fondo que lograba encontrar sus espacios de expresión incluso en un contexto como éste, tanto como cierta tolerancia a determinada literatura de connotaciones homoeróticas. Así, hemos de mencionar en primer lugar el Llibre d'Amic e d'Amat de Ramón Llull, que se guardaba de manifestaciones explícitas de carácter sexual, pero que contenía diversas piezas sobre un amor por el que los amigos perdían el juicio, y que hemos de analizar como piezas de arte homoerótico, cuyas expresiones literarias habían empezado a decaer considerablemente en el siglo XIII, dentro del contexto europeo ${ }^{38}$. Téngase

${ }^{35}$ Cf. Mérida 2001, p. 92. Por otra parte, para I. Bazán la justificación punitiva de la sodomía en el derecho alfonsí no sólo entroncaba con el derecho justinianeo, sino también con la herencia visigoda, $c f$. Bazán 2007, p. 437. Véase a este respecto el canon 3 del Concilio XVI de Toledo.

${ }^{36}$ Cf. Novelas 77 y 141.1. Por otra parte, véase la influencia que en la redacción de estas leyes justinianeas pudo tener la conceptualización del acto homosexual como un pecado contra natura que particularmente enojaba a la divinidad en los escritos de Philon de Alejandría, de Jean Crysosteme y de San Agustín. Para facilitar la labor del investigador, véase una colección de los escritos de estos autores referidos a esta temática en Borrillo, Colas 2005, pp. 66-72 y 99-109.

${ }^{37}$ Sobre esta subjetivación de la responsabilidad penal en el derecho castellano medieval, cf. Gómez 2012; Sainz 2006, p. 35; Lalinde 2001, pp. 363, 396-399; Orlandis 1945.

${ }^{38}$ Respecto del decaimiento de esta literatura en el siglo XIII, $c f$. Boswell 1993, p. 254. Con un carácter más genérico, respecto de la literatura homoerótica producida en la Edad Media, 
en cuenta que el afecto entre hombres descrito en estas composiciones era distinto del amor entre amigos referido en las colecciones de máximas de la época en la Península, que, a pesar de la intensidad con la que en ocasiones era descrito, no remitía al afecto que se profesan los enamorados y que apreciamos en muchas de las piezas del Llibre d'Amic e d'Amat ${ }^{39}$. De esta forma, y como muestra del carácter homoerótico de estas últimas, valga el siguiente ejemplo, entre tanto otros que podrían ser traídos a colación, sobre un varón que paseaba con la razón perdida por la ciudad, en un estado de locura de amor, cantando canciones de su amado:

Anava l'amich per una ciutat com a foll, cantant de son amat; e demanaren li les gents si avia perdut son seny. Respòs que son amat havia presso voler, e que ell li avia donat son enteniment; per açò era-li romàs tan solament lo remembrament, ab què remembrava son amat ${ }^{40}$.

En un género muy distinto, como es el género de las cántigas de escarnio y maldecir, cuyas piezas deben ser entendidas, dentro de su enorme complejidad simbólica, como vehículos de expresión que permitían transgre-

y más allá de la mencionada obra de J. Boswell, podrían citarse una gran pluralidad de trabajos, pero baste mencionar los siguientes, a los efectos del presente artículo: Woods 2001; Burgwinkle 2004; Crompton 2004; Castrillo 2009.

${ }^{39}$ Así pues, en Bocados de Oro podemos leer, entre otras máximas similares sobre las bondades de amistad entre los hombres, que: "El amigo puro que te ama, es mejor que tu hermano de padre e de madre que te cobdicia la muerte por te deseredar" (Bocados, f.5v). También sobre el amor entre amigos encontramos información relevante a estos efectos en otra colección de máximas de la época, Calila e Dilma, que contiene innumerables menciones de las que podríamos apoyarnos, sin embargo, baste la siguiente localizada en su capítulo III: "Et el ome de buena parte ama a su semejante de vna vez que se vean et por conoçençia de vndia e non mas; et el ome vil non pone su amor sy non por codiçia o conmiedo" (Calila, p. 286). Para un estudio específico sobre la amistad masculina en estas compilaciones de máximas de la época, $c f$. Haro 1995, pp. 242-263.

${ }^{40}$ L. Amic 54. Piezas de esta naturaleza, de un alto valor poético, y sobre un amor exacerbado, que conduce a la locura y al dolor del amigo, encontramos por doquier en la obra, como la siguiente:

“- Digues, foll, com no parles? Ni què es ço en què estàs embarbesclat, consirós?

Respòs: - En les bellees de mon amat e en lo ressemblament de les benanances e de les dolors que m'aduen e em donen amors." (L.Amic 72).

Respecto de cómo enamora el amado al amigo y de la fatiga y los placeres que le provoca, leemos lo siguiente: "L'amat enamora l'amich, e no el plany de son languiment, per ço que pus formament sia amat e en lo major languiment atrop l'amich plaer e reveniment" (L. Amic 31).

Sobre el carácter homoerótico de varias de las composiciones de este libro, así como para un estudio más profundo, respecto de las diferentes connotaciones sobre la amistad masculina en las piezas de esta obra y su significación, más allá del aspecto puramente erótico o sensual, cf. González-Casanova 1999, pp. 157-192. 
dir los tabúes del discurso social ${ }^{41}$, hallamos múltiples referencias a los actos de sodomía, que eran descritos no siempre con ánimo peyorativo o moralizante $^{42}$. Carecería de interés transcribirlas completamente, pero sí conviene aportar aquí el comienzo de una cantiga auto satírica escrita por Pero da Ponte, en la que, con ánimo burlesco y apoyado en la ambigüedad, él mismo se coloca frente a actos sodomitas en los siguientes términos:

Dom Tisso Pérez, queria oj'eu seer guardado do trebelho seu, e per perdoar-lh'o baton que fui meu; mais nom me poss'a seu jogo quitar; e, Tisso Pérez, que demo mi o deu, por sempre migo querer trebelhar? (v. 1-6)

Como un segundo ejemplo, de los diversos que podrían ser traídos a colación, el poeta Estevan de Guarda nos relata en una de sus cantigas una escena en la que un interlocutor lo amenaza con entablar un pleito en su contra, tras lo que el poeta expresa su intención de penetrarlo por el ano como represalia. De esta manera, apoyado en lo grotesco, y con una evidente intención jocosa, Estevan de Guarda otorga visibilidad a las relaciones sexuales entre varones en esta pieza, en los siguientes términos: Se mi a poserdes, tal vo-la porrei, que a sençades ben atá o cuu. (v. 18-19)

Pero, más allá de las composiciones amorosas del libro de Ramón Llull o de la grosería propia de estas cantigas de escarnio, también encontramos ejemplos dignos de mención dentro de la producción alfonsí. El caso más relevante es el de la General Estoria, donde hallamos algunas referencias homoeróticas recuperadas de los textos clásicos, principalmente en la narración de la vida de $\mathrm{Narciso}^{44}$. No obstante, no podemos afirmar que la intención del

${ }^{41}$ M.G. Videira Lopes analiza estas cantigas como una expresión particular del género carnavalesco medieval, que permitía transgredir libremente los tabúes establecidos, en Videira 1994.

${ }^{42}$ Sobre la visibilidad e incluso la tolerancia hacia la sodomía que se aprecia en algunas de estas cantigas, particularmente en las de Pero da Ponte, $c f$. Sodré 2004, 2006, 2007, 2007b, 2010.

${ }^{43}$ CEM 370. Respecto de este tipo de cantigas sobre homosexuales, además de las obras mencionadas en la anterior nota, podríamos enumerar una variedad de obras, pero, a los efectos del presente artículo, y dado que el asunto de las cantigas de escarnio y maldecir sólo nos interesa circunstancialmente en el presente estudio, baste mencionar la siguiente, para una primera aproximación a la materia: Blackmore 1999, pp. 195-221.

${ }^{44}$ Sobre el joven Narciso, del que se narra su hermosura en la General Estoria y se constata lo que otros varones lo codiciaban, se dice lo siguiente: "E cobdiciavan muchos mancebos e muchas mancebas e doncellas aver su compaña, mas tan grant fue e tan estraña la su sobervia en la fermosura d'aquella su edat e su mancebía que nin pudieron llegar ningunos mancebos nin mancebas nin ningunas donzellas" (GE 2.1: 223). Más allá de este relato, también se encuentran 
compilador fuese la de celebrar las relaciones sexuales entre varones, pues, por el contrario, incluso en la narración sobre Narciso apreciamos una censura en la traducción de los textos clásicos, que atenuó considerablemente la carga homoerótica del capítulo, bien por la propia obra alfonsí o bien mediante censores previos de la obra de Ovidio ${ }^{45}$. Este hecho debe servirnos para comprender la ausencia de determinadas narraciones en esta obra, así como para interpretar las referencias existentes en su justa medida, como ramas no podadas por la censura moralizante, que sí eliminó las referencias homoeróticas más explícitas respecto de la fuente original. A este respecto, no debe olvidarse la función de esta obra historiográfica, como la de otros vehículos de transmisión del saber en la época, como instrumento destinado al cumplimiento del plan divino, y, por lo tanto, a la salvación de los hombres ${ }^{46}$, bajo cuya comprensión podemos interpretar de mejor manera la censura o las adaptaciones que se aprecian respecto de determinadas prácticas propias del mundo pagano en este trabajo.

Por otra parte, más cercano a nuestro análisis es el caso de las Partidas, donde R.J. González-Casanova halla reminiscencias del paradigma de relaciones entre varones de los autores griegos en el título dedicado a la amistad de la Cuarta Partida ${ }^{47}$, ya que, ciertamente, dicho título está construido expresamente sobre la visión que los sabios antiguos tenían acerca de la amistad entre los hombres, con mención expresa a Aristóteles ${ }^{48}$. Así, y muy influidas por su Ética a Nicómaco ${ }^{49}$, en las Partidas podemos leer máximas como las siguientes: Amistad es cosa que ayunta mucho la voluntad a los omes, para amarse mucho. Ca segund dixeron los sabios antiguos, el verdadero amor passa todos los debdos ${ }^{50}$. En esta misma línea el código alfonsí nos dice que:

en la General Estoria otras referencias interesantes recuperadas del mundo clásico, como el rapto del joven Ganímedes ( $c f$. GE 2.1: 411) o la narración de la gran hermosura de Ninno ( $c f$. $G E$ 2.1: 296-300), entre otras menciones que podríamos traer a colación y que sería necesario abordar con suficiente detenimiento en un próximo artículo sobre la materia.

${ }^{45}$ Sobre este particular, y, en general, respecto de la censura en esta obra de los relatos paganos homosexuales, $c f$. Almeida et al. 2009; Almeida 2016; Salvo 2012, p. 415; Cristóbal 2015.

${ }^{46} C f$. Ruíz 2008, pp. 241-242.

${ }^{47}$ Cf. González-Casanova 1999.

${ }^{48}$ No tiene sentido presentar aquí un estudio sobre la opinión que tenían los principales pensadores griegos sobre las relaciones de amistad entre los hombres. Pero, específicamente en cuanto a las relaciones de tipo sexual, y respecto de Aristóteles, que es el único mencionado expresamente a este respecto por el legislador, ciertamente consideraba como saludable el hecho de que, bajo determinadas circunstancias, las relaciones entre los hombres se expresasen también en el plano de lo carnal, incluso entendía que las relaciones sexuales con efebos eran útiles a la sociedad al fin de evitar la sobrepoblación (cf. Política 2.7.5). Véase un estudio sobre las relaciones sexuales entre varones en los textos de Aristóteles en Borrillo, Colas 2005, pp. 44-51.

${ }^{49}$ En este sentido, compárense las reflexiones sobre la amistad en los libros VIII y IX del mencionado texto con las aquí mencionadas. Respecto de la recepción de la ética aristotélica en las Partidas, $c f$. Ferreiro 1988.

${ }^{50}$ Partidas 4.27.pr. 
Aristoteles que fizo departimiento naturalmente en todas las cosas deste mundo, dixo que eran tres maneras de amistad. La primera es, de natura. La segunda es, la que ome ha a su amigo, por vso de luengo tiempo, por bondad que aya en el. La tercera es, la que ome ha con otro, por algund pro, o por algund plazer que ha del, o espera auer ${ }^{51}$.

Máximas de esta naturaleza se encuentran a lo largo de todo el título XXVII de la Cuarta Partida. En todo caso, si bien estas afirmaciones estaban construidas sobre textos aristotélicos, lo cierto es que, tanto en su literalidad como en su significación, quedaban desprovistas de toda conexión con el amor sexual, y pueden equipararse a lo dispuesto en otros textos de la literatura sapiencial castellana de la época ${ }^{52}$. A este respecto, téngase en cuenta que, en cumplimiento de la teoría de la ley del código alfonsín ${ }^{53}$, la intención del legislador en materia de sexualidad era que ésta se vehiculase a través del sacramento del matrimonio, como se constataba claramente en la Cuarta Par$t i d a^{54}$, y la práctica sexual entre varones era castigada con la muerte en la Séptima, como estamos analizando en el presente artículo, por lo que bajo ningún concepto podríamos atribuir una intención diferente al legislador en su título dedicado a la amistad, aunque tomase por referencia un paradigma aristotélico de relaciones afectuosas entre varones, como resulta evidente.

Por último, respecto del pecado-delito del bestialismo, éste era el segundo delito regulado en este título, después del de sodomía, y era concebido también como un pecado contra natura ${ }^{55}$. Dicho ilícito aparecía ya regulado en el derecho canónico peninsular ${ }^{56}$, pero no en el derecho no eclesiástico de la península anterior a la obra alfonsí. Sin embargo, la fuente de la que bebía no hemos de hallarla en este derecho canónico peninsular, sino principalmente en los textos bíblicos, concretamente en el Levítico, de donde tomaba una muy

${ }^{51}$ Partidas 4.27.4.

${ }^{52} \mathrm{Cf}$. nota 39 .

${ }^{53}$ Como ya indicamos en Fernández-Viagas 2017c, véase la obligación del legislador alfonsí de adaptar sus normas al derecho divino en una pluralidad de leyes, dentro del código alfonsí: Partidas 1.pr, 1.1.4, 1.1.6, 1.1.9, 1.1.11, 1.1.16, 1.1.17, 1.1.18, 1.2.5, 1.2.9 y 2.2.4. Respecto de la teoría general de la ley en las Partidas, véase una lista de artículos y trabajos de interés en nuestro artículo mencionado en esta misma nota.

${ }^{54} \mathrm{Cf}$. Partidas 4.pr. Respecto de la institución del matrimonio como único vehículo deseado para la expresión de la sexualidad en las Partidas, así como respecto de la condena a los sodomitas en el código alfonsí, que dejan de manifiesto la repulsa del legislador hacia los actos sexuales entre varones, $c f$. González-Casanovas 1999, pp. 165-166. No obstante, también ha de tenerse en cuenta que en las Partidas se regulaba y se permitía, asimismo, la institución de la barraganía, si bien era concebida como un mal menor, cf. Partidas 4.14.pr.

${ }^{55}$ Cf. Salisbury 1991, 1994; Brundage 2003, pp. 211 y 215-216.

${ }^{56}$ Véase el canon 81 del Concilio III de Braga, que recogía lo dispuesto en el canon 16 de Ancyra, y el canon 4 de Coyanza. 
similar redacción ${ }^{57}$. Así, y al igual que en la Biblia, se prescribía la muerte tanto del hombre o de la mujer pecadora como de la bestia fornicaria, en los siguientes términos: Essa misma pena [de muerte] deue auer todo ome, o toda muger, que yoguiere con bestia, e deuen de mas matar la bestia para amortiguar la remembrança del fecho ${ }^{58}$.

En este punto, algún analista podría interpretar que la muerte de la bestia constituye, en el fondo, una muestra de responsabilidad penal del animal en la regulación de este delito ${ }^{59}$, sin embargo, nosotros entendemos que debe realizarse un análisis más complejo de esta ley, que trascienda la lógica meramente jurídica, acudiendo al auxilio de la sociología de las religiones. De esta manera, habría de interpretarse la muerte referida como una medida de separación radical del ser impuro, esto es, el animal fornicario, de la comunidad de seres profanos ${ }^{60}$, pues ello nos aporta una comprensión más profunda de estas tramas de significado, acudiendo al concepto sociológico de la impureza ${ }^{61}$. Además, ello nos permite encontrar explicaciones diferentes de las aportadas por el texto, que propiamente no contempla la muerte de la bestia como un castigo a causa de una responsabilidad penal, sino, al menos expresamente, como una medida para alejar el ilícito del recuerdo de los hombres ${ }^{62}$.

En todo caso, debe tenerse en cuenta que dicho acto sexual no era contemplado únicamente en las Partidas, dentro de las obras atribuidas a Alfonso $\mathrm{X}$, sino que también encontramos referencias interesantes más allá de las mismas. En este sentido, en la General Estoria el bestialismo era concebido desde una doble perspectiva, en función de las fuentes empleadas en cada caso. Así, cuando se tomaba como referencia relatos originarios del mundo clásico, el bestialismo aparecía vinculado con narraciones mitológicas, como la de la reina Pasife y el toro de Creta $^{63}$ o la de la seducción de Jupiter a Eu-

${ }^{57}$ Cf. Levítico 18: 23 y Levítico 20: 15-16.

${ }^{58}$ Cf. Partidas 7.21.2 in fine.

${ }^{59}$ Para un repaso sobre la responsabilidad penal de los animales en el derecho histórico español, $c f$. Lalinde 1983, p. 369; Sainz 2004, pp. 90-92.

${ }^{60}$ Respecto de la necesaria separación entre aquello que se convierte en sagrado (en su perspectiva impura en este caso) y la comunidad en las diferentes sociedades, para resguardar de la contaminación a la misma, desde una perspectiva sociológica y antropológica, $c f$. nota 33 .

${ }^{61}$ Sobre la sexualidad como posible fuente de impureza bajo un enfoque sociológico o antropológico la bibliografía es vastísima. No obstante, a los efectos del presente estudio, baste con citar los siguientes trabajos ya clásicos, que abordan el concepto de impureza y que, concretamente, aluden a la sexualidad como fuente de la misma, si bien desde distintos enfoques teóricos, $c f$. Durkheim 1964; Caillois 1984; Leeuw 1964; Douglas 1973; Girard 1972, p. 42.

${ }^{62}$ Respecto de la muerte del animal como medida para disipar el recuerdo del incidente, en el contexto jurídico y cultural de la época, $c f$. Hyde 1916; Salisbury 1991, p. 179; Evans 2006 , pp. 222-223. Respecto de las fuentes primarias, conviene repasar en este punto tanto el Decreto de Graciano (cf. Decretum C. 15, Q. 1, c. 4), como el de Ivo de Chartres (cf. Decretum 9.108).

${ }^{63} C f$. GE 2.1: 560-563. 
ropa convertido en toro ${ }^{64}$, pero adaptadas al carácter historiográfico de la obra alfonsí ${ }^{65}$, mientras que, cuando se tomaba como referencia a los textos bíblicos, el bestialismo era contemplado bajo el foco y la terminología cristiana, como un pecado que ensuciaba a las gentes y provocaba la ira divina, asociado a la sodomía ${ }^{66}$. Obviamente, fue bajo esta segunda perspectiva, imbuida de lo dispuesto en el Levítico, desde la que se reguló tal delito en el código de las Siete Partidas, pero no podemos olvidar la diversidad de narraciones que componían la magna obra literaria alfonsí, que empleaba textos de muy diferentes tradiciones culturales, ni tampoco podemos obviar otros textos de la península, que contemplaban con enorme rechazo estas prácticas sexuales, como era el caso del Liber Sancti Iacobi ${ }^{67}$.

Pero, más allá de estas apreciaciones, hemos de hacer notar que en los fueros castellano-leoneses del siglo XIII se percibía una vinculación entre determinados animales con una sexualidad desviada que debe ser abordada por el analista, y que nos ayuda a comprender la mentalidad de la época acudiendo a textos jurídicos que utilizaban a los animales como protagonistas de alusiones alegóricas sobre la sexualidad. En este sentido, véase la identificación que se trasluce de la regulación de los denuestos prohibidos en varios fueros municipales entre la mujer promiscua y la hembra del rocín en la familia de Cuenca-Teruel ${ }^{68}$. Dichos vocablos proferidos contra las mujeres, y recogidos en forma de delito de denuestos en este derecho foral, deben servirnos para comparar lo dispuesto en el título XXI de la Séptima Partida con unos textos en los que se deduce una concepción de determinada sexualidad animal como repugnante, como modelo de un comportamiento insano, en paralelo con lo dispuesto en el Viejo Testamento, donde se asocia a los adúlteros con caballos ${ }^{69} \mathrm{y}$ a las prostitutas con perros ${ }^{70}$, como bien recuerda J. Boswell ${ }^{71}$.

\footnotetext{
${ }^{64} C f . G E 2.1: 74-76$.

${ }^{65}$ Respecto de la inclusión de estas narraciones de origen pagano sobre el bestialismo en la General Estoria, véanse, como principales aportaciones, los estudios referidos al relato de Pasifae de Cristóbal 2016, p. 86; Lida 1958, p. 134; Salvo 2010-2011, p. 285; 2012 p. 485.

${ }^{66} C f$. GE 1.2: 543. El pecado ensuciaba al infractor y lo convertía en maldito, lo que tenía reseñables implicaciones simbólicas, $c f . G E$ 1.2: 921.

${ }^{67}$ Cf. C. Calixtinus 7.5: 549.

${ }^{68}$ Cf. F. Cuenca 11.29, Co. Valentino 2.1.24, F. Iznatoraf 251, F. Andújar 241, F. Zorita 253, F. Alcaraz 4.29, F. Alcaraz 237, F. Alarcón 237, F. Úbeda 28.2, F. Béjar 323, F. Plasencia 70, F. Sabiote 252 y F. Brihuega 91. Por otra parte, más allá de estos documentos escritos, véase la identificación de determinados animales, como la liebre, el macho cabrío o el simio, con el vicio de la lujuria en manifestaciones escultóricas románicas del norte peninsular, $c f$. Lecanda y Tobalina 2012.

${ }^{69} \mathrm{Cf}$. Jeremías 5: 8.

${ }^{70} \mathrm{Cf}$. Deuteronomio 23: 18 .

${ }^{71}$ Cf. Boswell 1993, p. 147.
} 
Por último, y en materia procesal, hemos de entender, aunque no se mencionara expresamente en las Partidas, que la acción para acusar al hombre o a la mujer fornicaria era también pública en este caso, por analogía respecto de la regulación del delito de sodomía antes analizado.

\section{CONCLUSIONES}

Como hemos visto, la Séptima Partida de Alfonso X regulaba en su título XXI dos pecados contra natura considerados también como delitos por la legislación regia. El acto sodomítico quedaba regulado bajo la influencia del derecho romano oriental, en concreto bajo el influjo de las Novelas de Justiniano, que lo configuraban como una unión sexual contra natura que ofendía especialmente a la divinidad y que sólo podían cometer los varones, quienes eran castigados con independencia de que fueran activos o pasivos en dicho acto. Con este esquema básico lo encontramos también articulado en el código alfonsí, en los términos analizados en el presente artículo.

A lo largo de este trabajo, hemos podido transcender el análisis meramente técnico-jurídico, para abordar la cuestión desde otros enfoques, que nos permiten realizar una interpretación más rica de las normas y construir una pieza de historiografía cultural. De esta manera, hemos interpretado la pena prevista para los sodomitas en las Partidas como una medida de separación radical entre los seres devenidos impuros y la comunidad, necesitada de protección, bajo el auxilio de los estudios sociológicos y antropológicos sobre el fenómeno de lo sagrado. Por otra parte, estos estudios, y en concreto la obra de R. Girard, pueden servirnos para concebir al sodomita bajo la categoría del chivo expiatorio y para una mejor comprensión del esquema de persecución en su contra previsto por los legisladores de la época en la Corona de Castilla.

El segundo pecado contra natura regulado en dicho título XXI es el del bestialismo, que también hemos analizado utilizando fuentes no sólo jurídicas, para comprender el contexto en el que hemos de insertar estas normas, y apoyándonos no sólo en la ciencia jurídica, sino en otras disciplinas de las ciencias sociales, que nos aportan categorías y herramientas interpretativas útiles para nuestra investigación. Por otra parte, desde el punto de vista de las fuentes, la regulación de este delito no respondía a patrones del derecho romano, como en el anterior caso, sino que bebía principalmente de los textos bíblicos, lo que explica en buena medida su lógica regulatoria. 


\section{BIBLIOGRAFÍA CITADA}

FUENTES PRIMARIAS: JURÍDICAS

Albareda y Herrera, Manuel (ed.) (1925), El fuero de Alfambra, Madrid, Tip. de Archivos, Bibliotecas y Museos.

Arboledas Porras, Pedro Andrés (ed.) (1994), El fuero de Sabiote, "Cuadernos de Historia del Derecho" 1 pp. 243-441.

Calleja Puerta, Miguel (ed.) (2003), El fuero de Llanes. Edición crítica, Oviedo, Sueve.

Castro, Américo; Onís, Federico de (1916), Fueros leoneses de Zamora, Salamanca, Ledesma y Alba de Tormes, Madrid, Centro de Estudios Históricos.

Códigos españoles concordados y anotados, Madrid, 1847 [Contiene el Fuero Juzgo, el Fuero Real, el Fuero Viejo y el Liber Iudiciorum.]

El libro de los fueros de Castiella (1924), Barcelona, Universidad de Barcelona.

Fita Colomé, Fidel (ed.) (1889), El fuero de Uclés, "Boletín de la Real Academia de Historia" 14/4, pp. 302-355.

Friedberg, Emil (ed.) (1879), Corpus Iuris Canonici, Lipsiae, Bernhard Tauchnitz.

García del Corral, Ildefonso (2004), Cuerpo del derecho civil romano, Valladolid, Lex Nova.

García de Valdeavellano, Luis (ed.) (1983), El fuero de León. Comentarios, Madrid, Hullera Vasco-Leonesa.

García Oliva, Dolores (trans.) (2016), Fuero romanceado de Cáceres, Ayuntamiento de Cáceres, goo.gl/FJwV1j [Consulta: 09/08/2016].

González, Francisco (ed.) (1850), Colección de cánones de la Iglesia Española, Madrid, Imp. de Anselmo Santa Colona y Compañía.

González Palencia, Ángel; González Palencia, Inocenta (eds.) (1932), El fuero latino de Albarracín, Madrid, Tip. de Archivos.

Gorosh, Max (ed.) (1950), El Fuero de Teruel según los Mss. 1-4 de la Sociedad Económica Turolense de Amigos del País y 802 de la Biblioteca Nacional de Madrid, Estocolmo, LHMA.

Gregorio IX, Decretales, códice de la Librería del Congreso de EEUU, Mainz, Peter Schoeffer, 1473.

Gutiérrez Cuadrado, Juan (ed.) (1979), Fuero de Úbeda, Valencia, Universidad de Valencia.

Herculano, Alexander (ed.) (1856), Portugaliae Monumenta Historica, Leges et Consuetudines, Lisboa, Academia das Ciências de Lisboa [Contiene los fueros de Alfaiates, Castelo Bom, Castelo Melhor y Santarém]. 
Jaume I, Furs de Jaume I (1238-1271), Valencia, Generalitat Valenciana Universitat Jaume I, 2016, goo.gl/MkXiDu [Consulta: 23/10/2016].

Keniston, Hayward (ed.) (1965), Fuero de Guadalajara (1219), Nueva York, Elliot Keniston.

Lindley Cintra, Luis F. (ed.) (1984), A Linguagem dos foros de Castelo Rodrigo: seu confronto com a dos foros de Alfaiates, Castelo Bom, Castelo Melhor, Coria, Cáceres e Usagre, Lisboa, Casa da Moeda.

López, Gregorio (1576), Las Siete Partidas del Sabio Rey don Alonso..., Salamanca, Imp. de Domingo de Portonariis.

Luño Peña, Enrique (ed.) (1927), Legislación foral de don Rodrigo Jiménez de Rada, Zaragoza, Universidad de Zaragoza [Contiene el fuero de Brihuega].

Majada Neila, Jesús) (ed.) (1986), Fuero de Plasencia, Plasencia, Ayuntamiento de Plasencia.

Martín de Palma, María Teresa (ed.) (1984), Los fueros de Villaescusa de Haro y Huete, Málaga, Universidad de Málaga.

Martín Lázaro, Antonio (ed.) (1926), Fuero castellano de Béjar (siglo XIII), Madrid, Tip. de Archivos.

Martínez Martínez, Faustino (ed.) (2003), Antología de textos forales del antiguo reino de Galicia (siglos XII-XIV), "Cuaderno de Historia del Derecho" 10, pp. 247-352 [Contiene los fueros de Allariz, Bonoburgo de Caldelas, Milmanda, Oviedo, Parga y Ribadavia].

Muñoz y Romero, Tomás (ed.) (1847), Colección de fueros municipales y cartas pueblas de los reinos de Castilla, León, Corona de Aragón y Navarra, Madrid, Imp. de José María Alonso [Contiene los fueros de Lara, Medinaceli y Peralta].

Oliver, Bienvenido (ed.) (1881), Libre de les costums generals escrites de la insigne ciutat de Tortosa, Madrid, Imp. De Miguel Ginesta.

Quesada Huertas, Pablo (ed.) (2006), El fuero de Andújar: estudio y edición, Jaén, Universidad de Jaén

Roudil, Jean (ed.) (1962), El fuero de Baeza, La Haya, Van Goor Zonen.

Roudil, Jean (ed.) (1968), Les fueros d'Alcaraz et d'Alarcón, Estrasburgo, Faculté des Lettres et Sciences Humanes de Strasburg [Contiene las variantes del fuero de Alcázar].

Sánchez, Galo (ed.) (1919), Fueros castellanos de Soria y Alcalá de Henares, Madrid, Centro de Estudios Históricos.

Sancho Izquierdo, Miguel (ed.) (1916), El fuero de Molina de Aragón, Madrid, Librería General de Vitoriano Suárez

Sáenz Sánchez, Emilio (ed.) (1949), El fuero de Coria, Madrid, Instituto de Estudios de Administración Local.

Tilander, Gunnar (ed.) (1956), Vidal Mayor, Lund, LHMA. 
Ureña y Smenjaud, Rafael (ed.) (1911), Fuero de Zorita de los Canes según el códice 217 de la Biblioteca Nacional (siglos XIII al XIV) y sus relaciones con el fuero latino de Cuenca y el romanceado de Alcázar, Madrid, Est. Tip. de Fortanet.

Ureña y Smenjaud, Rafael (ed.) (1935), Fuero de Cuenca (formas primitiva y sistemática: Texto castellano y adaptación al fuero de Iznatoraf), Madrid, Tip. de Archivos [Incluye el códice valentino].

Ureña y Smenjaud, Rafael; Bonilla y San Martín, Adolfo (eds.) (1907), Fuero de Usagre (siglo XIII). Anotado con las variantes del de Cáceres, Madrid, Hijos de Reus Editores.

\section{FUENTES PRIMARIAS: LITERARIAS}

Bocados de oro (1507), Toledo, goo.gl/c3pQbV [Consulta: 16/11/2016]

Castor de Caunedo, Nicolás (trad.) (1854), Un Cronicón del siglo IX, "Semanario Pintoresco Español" 22, pp. 169-173 [Contiene la crónica de Alfonso III].

Chartres, Ivo de (2015), Decretum, Konstanz, goo.gl/1s4br7 [Consulta: 04/05/2017].

Damiano, Pedro (1853), S. Petri Damiani... Opera Omnia, goo.gl/nSkn6F [Consulta: 04/05/2017].

García Valdés, Manuela (ed.) (1982), Política de Aristóteles, Madrid, Gredos.

García Blanco, María José (ed.) (2014), Liber Sancti Jacobi: Codex Calixtinus, Santiago de Compostela, Xunta de Galicia.

Gómez Moreno, Manuel (ed.) (1921), Introducción a la Historia Silense con versión castellana de la misma y de la crónica de Sampiro, Madrid, Centro de Estudios Históricos.

Graciano (1879), Decretum, Lipsiae, goo.gl/mefPgq_[Consulta: 04/05/ 2017].

Gregorio IX (1473), Decretales, códice de la Librería del Congreso de EE.UU., Mainz, goo.gl/WAAj9S [Consulta: 04/05/2017].

Jörg Dóhla, Hans (ed.) (2007), El libro de Calila e Dimna (1251), Zurich, Universidad de Zurich .

Llull, Ramón (1972), Doctrinal Pueril, Barcelona, Editorial Barcino.

Llull, Ramón (2006), Libro de amigo y amado, Barcelona, DVD Ediciones Editorial Barcino.

Longère, Jean (ed.) (1965), Alain de Lille. Liber poenitentialis, Lovaina, Editions Nauwelaerts.

Madre, Aloisius (ed.) (1998), Raimundi Lulli Opera Latina. 22, 130-133 in Monte Pessulano et Pisis anno 1308 composita, Turnholt, Brepols [Contiene la obra: Fèlix o Llibre de meravelles]. 
Martínez Manzano, Teresa; Calvo Martínez, Tomas; Pallí Bonet, Julio; Calvo Martínez, Tomás (eds.) (1982), Ética de Aristóteles, Madrid, Gredos.

Melttman, Walter (ed.) (1981), Cantigas de Santa María de Alfonso X el Sabio, Vigo, Edicións Xerais de Galicia.

Menéndez y Pidal, Ramón (ed.) (1906), Primera crónica General de España: Estoria de España que mandó componer Alfonso el Sabio y se continuaba bajo Sancho IV en 1289, Madrid, Bailly-Bailliére e hijos.

Nova Vulgata (1879), Roma, goo.gl/jJC9V9 [Consulta:15/11/2016].

Peñafort, Ramón de (1603), Summa de poenitentia et matrimonio cum glossis Ioannis de Friburgo, Roma, Joannes Tallinus imp.

Pujol, Julio (ed.) (1926), Crónica de España por Lucas, obispo de Túy, Madrid, Real Academia de la Historia.

Riesco Chueca, Pilar (ed.) (1995), Pasionario Hispánico (Introducción, Edición Crítica y Traducción), Sevilla, Universidad de Sevilla.

Rodrigues Lapa, Manuel (ed.) (1965), Cantigas d'escarnho e de mal dizer. Ediçáo crítica, Lisboa, Editorial Galaxia.

Santa María Egipcíaca (2008), Alicante, Biblioteca Virtual Miguel de Cervantes, goo.gl/gJJ1hD [Consulta:15/11/2016].

Sánchez-Prieto Borja, Pedro (ed.) (2009), General Estoria, Madrid, Fundación José Antonio de Castro.

Sánchez-Prieto Borja, Pedro; Díaz Moreno, Rocío; Trujillo Belso, Elena (eds.), Edición de textos alfonsíes en Real Academia Española: Banco de datos (CORDE), Libro complido en los judizios de las estrellas, Real Academia Española de la Lengua, goo.gl/SJw94c [Consulta: $24 / 08 / 2017]$.

Suárez, Manuel; Campelo, José (1950), Historia Compostelana: o sea hechos de D. Diego Gelmírez, primer arzobispo de Santiago, Santiago de Compostela - Porto, Biblioteca digital de Galicia.

Tomás de Aquino (2001), Suma Teológica, Madrid, Biblioteca de autores cristianos.

Worms, Brucardo, Decretum. Códice 119 de la Biblioteca de la Catedral de Colonia (Dom Hs. 119), goo.gl/FfP3CA [Consulta: 04/05/ 2017].

\section{ESTUDIOS}

Almeida Cabrejas, Belén (2012), Maldad y pecado en la General estoria de Alfonso X El Sabio, "Revista de El Colegio de San Luis" 6/12, pp. 10-38.

Almeida Cabrejas, Belén; Trujillo Belso, Elena (2009), Censura y modificación ideológica en la Quinta Parte de la General Estoria de Alfonso X el Sabio, "Diálogo de la Lengua" 1, pp. 165-178. 
Barrero García, Ana María; Alonso Martín, María Luz (1999), Textos de derecho local español en la Edad Media: catálogo de fueros y costums municipales, Madrid, CSIC.

Bazán, Iñaki (2007), La construcción del discurso homofóbico en la Europa cristiana medieval, "En la España Medieval” 30,pp. 433-454.

Bermejo Cabrera, José Luis (2011), García-Gallo ante la obra legislativa de Alfonso X, "Cuadernos de historia del derecho" 18, pp.163-191.

Blackmore, Josiah (1999), The Poets of Sodom, en Blackmore, Josiah; Hutcheson, Gregory S. (eds.), Queer Iberia. Sexualities, Cultures, and Crossings from the Middle Ages to the Renaissance, Durham, University of Duke, pp. 195-221.

Borrillo, Daniel; Colas, Dominique (2005), L' homosexualité de Platon à Foucault, París, Plon.

Boswell, John (1993), Cristianismo, tolerancia social y homosexualidad: los gays en Europa occidental desde el comienzo de la Era cristiana hasta el siglo XIV, Barcelona, Muchnik.

Brundage, James A. (2000), La ley, el sexo y la sociedad cristiana en la Europa medieval, Madrid, Fondo de Cultura Económica de España.

Burgwinkle, William E. (2004), Sodomy, Masculinity, and Law in Medieval Literature: France and England, 1050-1230, Cambridge, University of Cambridge.

Callón, Carlos (2011), Amigos e sodomitas. A configuración da homosexualidade na Idade Media, Santiago de Compostela, Sotelo Blanco.

Camocho Cantudo, Miguel Ángel (2012), Sodomía. El crimen y pecado contra natura o historia de una intolerancia, Madrid, Dykinson.

Carrasco Manchado, Ana Isabel (2008), Entre el delito y el pecado contra naturam, en Carrasco Manchado, Ana Isabel; Rábade Obrado, María del Pilar (coords.), Pecar en la Edad Media, Madrid, Sílex, pp.114-125.

Castrillo de la Fuente, José María (2009), Actitud hacia la homosexualidad en la Edad Media, en Val Valdivieso, María Isabel; Martínez Sopena, Pascual (coords.), Castilla y el mundo feudal: homenaje al profesor Julio Valdeón, Valladolid, Junta de Castilla y León - Universidad de Valladolid.

Craddock, Jerry R. (1981), La cronología de las obras legislativas de Alfonso X, "Anuario de Historia del Derecho Español" 51, pp. 386-400.

Crompton, Louis (2004), Homosexuality \& Civilization, Cambridge, Belknap Press.

Douglas, Mary (1973), Pureza y peligro, Madrid, Siglo XXI Editores.

Durkheim, Emilie (1968), Las formas elementales de la vida religiosa, Buenos Aires, Shapire. 
Eliade, Mircea (2014), Lo sagrado y lo profano, Barcelona, Paidós.

Evans, Edward Payson (2006), The Criminal Prosecution and Capital Punishment of Animals, New Jersey, The Lawbook Exchange.

Fernández-Viagas Escudero, Plácido (2016), La honra del marido como bien jurídico protegido en el delito de adulterio: Un estudio de las Partidas a la luz de sus antecedentes normativos y de su contexto cultural, "Clío \& Crimen" 16, pp. 53-74.

Fernández-Viagas Escudero, Plácido (2017), El rey en las Partidas de Alfonso $X$ : Su vicariato divino y su caracterización bajo esquemas de sacralidad, "Hispania Sacra" 139, pp. 61-80.

Fernández-Viagas Escudero, Plácido (2017), Las relaciones sexuales entre miembros de minorías religiosas y mujeres cristianas en la Séptima Partida, "En la España Medieval" 40, pp. 269-308.

Fernández-Viagas Escudero, Plácido (2017), "De los alcahuetes”. Un estudio del título XXII de la Séptima Partida, "Cuadernos de Historia del Derecho" 24, pp. 219-242.

Ferreiro Alemparte, Jaime (1988), Recepción de las éticas y de la política de Aristóteles en las Siete Partidas del Rey Sabio, "Glossae" 1, pp. 97-133.

Fone, Byrne (2000), Homophobia. A history, Nueva York, Picador.

Gauthier, A. (1977), La sodomie dans le droit canonique médiévale, en Roy, Bruno (ed.), L'érotisme au moyen âge: études présentées au troisième colloque de l'Institut d'études médiévales de l'Université de Montréal, Montreal, L'Aurore, pp. 109-122.

Geertz, Clifford (2003), La interpretación de las culturas, Barcelona, Gedisa. Girard, René (1986), El chivo expiatorio, Barcelona, Anagrama.

Girard René (1972), La violencia y lo sagrado, Barcelona, Anagrama.

Goffman, Erving (2006), Estigma. La identidad deteriorada, Buenos Aires Madrid, Amorrortu.

Goodich, Michael (1979), The Unmentionable Vice, Santa Barbara - Oxford, $\mathrm{ABC}$ - Clio.

Gómez Pavajeau, Carlos Arturo (2012), Derecho penal en la Edad Media, Bogotá, Universidad de Colombia.

González-Casanova, Roberto J. (1999), Male Bonding as Cultural Construction in Alfonso X, Ramon Llull and Juan Manuel, en Blackmore, Josiah; Hutcheson, Gregory S. (eds.), Queer Iberia. Sexualities, Cultures, and Crossings from the Middle Ages to the Renaissance, Durham, University of Duke, pp. 157-192.

Haro Cortés, Marta (1995), Los compendios de castigos del siglo XIII: Técnicas narrativas y contenido ético, Valencia, Universidad de Valencia. 
Hyde, Walter Woodburn (1916), The Prosecution and Punishment of Animals and Lifeless Things in the Middle Ages and Modern Times, "University of Pennsylvania Law Review ans American Law Register" 64/7, pp. 696-730.

Hopman, Jan (2000), La sodomía en la historia de la moral eclesial, en Olavarría, José; Parrini, Rodrigo (eds.), Masculinidades. Identidad, sexualidad y familia, Santiago de Chile, Flacso, pp. 113-122.

Johansson, Warren; Percy, William, A. (2000), Homosexuality, en Bullough, Vem L.; Brundage, James A. (eds.), Handbook of Medieval Sexuality, Nueva York, Routledge, pp. 167-179.

Jordan, Mark (2002), La invención de la sodomía en la teología medieval, Barcelona, Laertes

Lalinde Abadía, Jesús (1983), Derecho histórico español, Barcelona, Ariel.

Lecanda Esteban, José Ángel; Tobalina Pulido, Leticia (2012), Pecado y penitencia: mentalidades y sociedad en la Plena Edad Media a través de la iconografía románica del Camino de Santiago en Araba, "Clío \& Crimen" 9, pp. 397-570.

Leeuw, Gerardus van der (1964), La fenomenología de la religión, México Buenos Aires, Fondo de Cultura Económica.

Lida de Maikel, María Rosa (1958), La "General estoria": notas literarias y filológicas (I), "Romance Philology", pp. 111-142.

López Beltrán, María Teresa (2010), Delitos sexuales en Castilla a finales de la Edad Media: el pecado nefando, en Carzolio de Rossi, María Inés; Fernández Prieto, Rosa Isabel; Lagunas, Cecilia, El Antiguo Régimen: una mirada de dos mundos: España y América, Buenos Aires, Prometeo Libros.

Madero, Marta (1992), Manos violentas, palabras vedadas, Madrid, Taurus.

Martin, Georges (2000), Alphonse X de Castille, roi et empereur. Commentaire du premier titre de la Deuxième Partie, "Cahiers de linguistique médiévale" 23, pp. 323-348.

Mérida Jiménez, Rafael Manuel (2007), Sodoma, del Viejo al Nuevo Mundo, "Treballs de la Societat Catalana de Geografia" 64, pp. 89-102.

Molina, Fernanda (2010), La herejización de la sodomía en la sociedad moderna, "Hispania Sacra" 62/126, pp. 539-562.

Moore, Roger I. (1989), La formación de una sociedad represora, Barcelona, Editorial Crítica

Navarro, Germán (2015), Las imágenes de la diversidad sexual en la Edad Media, en Huerta, Ricardo; Alonso-Sanz, Amparo (eds.), Educación artística y diversidad sexual, Valencia, Universitat de Vàlencia, pp. 61-78. 
Orlandis Rovira, José (1945), Sobre el concepto del delito en el Derecho de la alta Edad Media, "Anuario de Historia del Derecho Español” 16, pp. 112-192.

Ortega Baún, Ana E. (2011), Sexo, pecado, delito. Castilla de 1200 a 1350, [S.1.], Bubok.

Otto, Rudolf (1965), Lo santo. Lo racional y lo irracional en la idea de Dios, Madrid, Revista de Occidente.

Riera i Sans, Jaume (2014), Sodomites catalans. Història i vida (segles XIIIXVIII), Barcelona, Editorial Base.

Ries, Julien (1989), Lo sagrado en la historia de la humanidad, Madrid, Ediciones Encuentro.

Ruíz Gómez, Francisco (2008), La ilusión de la identidad en el imaginario medieval según las Partidas, "Edad Media: revista de historia" 9, pp. 239-261.

Sáez Martínez, Gil José (2015), Aproximación histórica a los abusos sexuales a menores, "Eguzkilore" 29, pp. 137-170.

Sainz Guerra, Juan (2004), La evolución del Derecho penal en España, Jaén, Universidad de Jaén.

Salisbury Joyce E. (1991), Sex in the Middle Ages. A Book of Essays, Nueva York, Garland Publishing.

Salisbury, Joyce E. (1994), The Beast Within. Animals in the Middle Ages, Londres, Routledge.

Salvo García, Irene (2010-2011), Usos y finalidades de breves fragmentos de fuente ovidiana en la General Estoria, "Alcanate" 7, pp. 269-292.

Salvo García, Irene (2012), Ovidio en la General Estoria de Alfonso, Madrid, Universidad Complutense (tesis doctoral).

Sodré, Paulo Roberto (2004), Os homens entre si, en Lopes, Denilson; Bento, Berenice; Aboud, Sergio; Garcia, Wilton (orgs.), Imagem \& diversidade sexual: estudos da homocultura, São Paulo, Nojosa, pp. 246-253.

Sodré, Paulo Roberto (2006), A sodomía no "jugar de palabras" de Estevão da Guarda, "Aletria: revista de Estudios Literarios" 13, pp. 125-132.

Sodré, Paulo Roberto (2007), Ainda sobre a sodomía na sátira galegoportuguesa, "Revista do Centro de Estudos Portugueses" 27/37, pp. 123-149.

Sodré, Paulo Roberto (2007), Unos con otros contra natura, e costumbre natural: sobre a sodomía na sátira galego-portuguesa, "Signum" 9, pp. 121-150.

Sodré, Paulo Roberto (2010), O riso no jogo e o jogo do riso na sátira galegoportuguesa, Vitória, Edufes. 
Solórzano Telechea, Jesús Ángel (2005), Justicia y ejercicio del poder: la infamia y los delitos de lujuria en la cultural legal de la Castilla medieval, "Cuadernos de Historia del Derecho" 12, pp. 313-353.

Solórzano Telechea, Jesús Ángel (2006), Justicia y represión sexual en la Corona de Castilla entre finales del siglo XII y principios del XVI, en Gonthier, Nicole (ed.), L'exclusion au Moyen Âge, Lyon, Université Jean Moulin, pp. 155-166.

Solórzano Telechea, Jesús Ángel (2007), Fama publica, infamy and defamation: judicial violence and social control of crimes against sexual morals in medieval Castile, "Journal of Medieval History" 33, pp. 398-413.

Solórzano Telechea, Jesús Ángel (2008), Diffamation, infamie et justice: l'usage judiciaire de la violence dans les villes de la Couronne de Castille, en Follain, Antoine; Lemesle, Bruno; Nassiet, Michel; Pierre, Éric; Quincy-Lefebvre, Pascale (dirs.), La violence et le judiciaire du Moyen Âge à nos jours, Rennes, Presses Universitaires de Rennes, pp. 187-197.

Solórzano Telechea, Jesús Ángel (2012), Poder, sexo y ley: la persecución de la sodomía en los tribunales de la Castilla de los Trastámara, "Clío \& Crimen" 9, pp. 285-396.

Spencer, Colin (2005), Histoire de l'homosexualité de l'antiquité à nos jours, París, Pocket.

Videira Lopes, Maria da Graça (1994), A sátira nos cancioneiros medievais galego-portugueses, Lisboa, Estampa.

Widengren, Geo (1976), Fenomenología de la religión, Madrid, Ediciones Cristiandad.

Woods, Gregory (2001), Historia de la literatura gay, Madrid, Akal.

Fecha de recepción del artículo: septiembre 2017

Fecha de aceptación y versión final: junio 2018 